\title{
Reflective Annotations: On Becoming a Scholar
}

\author{
Socialization for Teaching \\ Mark Alexander \\ Doctoral Learner, General Psychology \\ Grand Canyon University
}

In most institutions there are four principal areas of faculty work: research, service (institutional and disciplinary), community outreach, and pedagogical activity. Socialization is the process by which doctoral learners acquire the necessary knowledge, skills, and dispositions to be effective in each of these areas. The existing literature on doctoral socialization has defined the following set of core competencies to support these four areas: conceptual understandings (the development of a professional identity, expertise in the discipline); knowledge and skills in the above four areas (including specific skills regarding teaching and learning); interpersonal skills (written and oral communication collaboration); and professional habits (ethics and integrity, professional development). Additionally, there are a number of stakeholders-students, faculty, departments, universities, and external agencies-that play a role in the successful socialization of doctoral learners.

Although the desired outcomes for doctoral preparation are clear, and are supported by a robust body of research, in practice there is greater emphasis on certain areas of doctoral learning than on others. Most doctoral programs have a strong focus on the development of skills and knowledge around research and expertise in the discipline. With regard to pedagogical activity, however, it is evident that there is little, if any, formal and intentional preparation for teaching in most doctoral programs. What socialization does occur is often a result of interacting with faculty members and/or of any teaching assignments the doctoral student may have at the institution. Does this discrepancy reflect a flaw in the design of doctoral

If...online doctoral programs are going to develop doctoral learners whose skill addresses the competencies identified in the literature, the design of those programs must include mechanisms arising from the modality. programs? Or do certain competencies in reality have greater value in the academic community than others? For an online doctoral student, the availability of a teaching assistantship is rare or even nonexistent. Interaction with faculty is primarily asynchronous. So how will I develop the core competencies described in the literature? Or will my experience mimic that of the traditional doctoral student, with less than adequate emphasis on the preparation for a teaching role?

If institutions that provide online doctoral programs are going to develop doctoral learners whose skills address the competencies identified in the literature, the design of those programs must include mechanisms to address the differences arising from the modality. Programs should be designed with the core competencies in mind. Learning activities that develop skill and knowledge regarding teaching and learning must be built into the curriculum. Residencies that include the opportunity to discuss teaching and learning should be available. As a doctoral learner, I have a measure of responsibility to seek out opportunities to address areas that I need to develop. I'm certain that being an online doctoral student is a very different experience from that of a traditional campus doctoral student. However, if we accept the development of core competencies as being key to a doctoral program, then our focus shifts from the challenges and variations in experience to the development of the learner. 


\title{
Reference
}

McDaniels, M. (2010). Doctoral student socialization for teaching roles. In S.Gardner $\&$ P. Mendoza (Eds.), On becoming a scholar: Socialization and development in doctoral education (pp. 29-44). Sterling, VA: Stylus.

\section{Socialization for Service}

\author{
Caroline Taylor \\ Doctoral Learner, Organizational Leadership \\ Grand Canyon University
}

The role of the faculty member extends beyond guiding students through the process of research and writing components required for graduate school. More importantly, faculty members socialize students into the culture of the discipline. They clarify and reinforce what is expected of the scholar. They lead by example. There are three important responsibilities for each member of faculty: research, teaching, and service. Depending on the type of college or university the faculty member is a part of, the duties for each responsibility may vary. However, the three are still consistent. The first two, teaching and research, are somewhat selfexplanatory. Service is where the grey areas tend to blend for most faculty and sometimes can be overlooked. It is important that each area be clearly defined and that duties be understood as the graduate student evolves into the role of faculty member. As graduate students learn the responsibilities of professional faculty, it is crucial not to underestimate the importance of all aspects of service.

Service is an expression of the impulse or desire to make a contribution. Winkle-Wagner, Johnson, Morelon-Quainoo, and Santiague (2010) present three components of service, which are analyzed in this reflective article: service as part of the mission for higher education, service within higher education, and service beyond campus. These are somewhat broad in definition and are adaptable to the type of institution the faculty member serves. From my perspective as an online doctoral learner, part of the mission of service is to prepare graduate students to contribute to society as a whole. This service is particularly suited for the area in which the online doctoral student lives and works because it extends the campus to their community, as in the case of, the doctoral learner researching the benefits of community health fairs.

Service within higher education refers to how faculty support the internal functioning of the institution and their discipline, and how this support contributes to the success of their institution. Discipline associations and universities are known by the quality of their faculty. Those that serve on committees and share duties such as hiring contribute to a shared governance of the institution. This can be a bit challenging for the online doctoral learner, since he or she has not actually taken on the responsibilities of a faculty member. However, some associations and universities appoint a student member. This appointment orients the face-to-face student to the duties associated with the internal functioning of the institution. This could also be an avenue for the online doctoral learner.

Finally, there is service that extends beyond the campus; for example, serving local and state government by providing expertise in the realm of decision making and public policy. This service is particularly suited for the area in which the online doctoral student resides, because it extends the campus to local governing bodies. Due to the fact that online doctoral learners reside all around the world, the 
institution and its faculty service have the potential to make an enormous impact in so many areas.

Throughout my experience as an online doctoral learner, I am able to refine my skills as a researcher, building theoretical knowledge so that I can walk with confidence as an emerging scholar. Many online doctoral programs state that they are intended for professionals who want to make a difference in their field and in their communities. My experience was different, however; it allowed me to collaborate with doctoral faculty independently, as well as within the program. Together, we focused on real problems to come up with solutions using research and reflective dialogue. This program included group discussions, dissertation preparation throughout the program, and residencies. Every week in our group discussions, we addressed in-depth, thought-provoking questions that required the learner to interact and provide real insights based on research. Unique to many other doctoral programs, and starting with the initial course, the learner is required find their passion. Within that passion, he or she will discover their dissertation topic to research. Indeed, finding and knowing your passion is essential to completing your dissertation. This dissertation process started in the opening course and continued with literature research, writing, and being matched with a dissertation chair in my field of study, to guide me throughout the rest of the degree program. Doctoral residencies provided opportunities to network and study with professionals in my field, in a face-to-face environment. I was able to get detailed guidance as I prepared to write my dissertation. During residency, the learners have the opportunity to practice their group research and presentation skills. This experience as a doctoral learner in an online program has enhanced my leadership skills in my organization and allowed me to make a difference in the community through the use of research, theory, and practical experience

\title{
Reference
}

Ward, K. (2010). Doctoral student socialization for service. In S. Gardner \& P. Mendoza (Eds.), On becoming a scholar: Socialization and development in doctoral education (pp. 57-76). Sterling, VA: Stylus.

\section{Sense of Belonging}

\author{
Scott Greenberger \\ Doctoral Learner, Organizational Leadership \\ Grand Canyon University
}

A sense of belonging affects academic persistence in graduate programs, especially for students of color, who are the ethnic minority. The qualitative, grounded-theory study in this chapter by Gardner (2010), which was part of a larger multiple institution research effort, explored the socialization factors that affect the persistence of students of color in campus-based, advanced-degree programs. The sample population included eight first-year graduate students enrolled in a university in the Midwestern United States. Four of the participants were women of color (i.e., one Latino and three African-American students) enrolled in an education doctoral program, while the other four participants were AfricanAmerican law students (i.e., one male and three female). The researchers emailed all students in each discipline and employed a purposeful sampling technique to select the participants. Data collection used semi-structured focus groups in which participants shared their experiences with the researchers. The data were coded and then analyzed through an iterative process that included participants reading drafts of the study to provide further clarity on interpretations of the interviewers. The findings supported the theoretical framework suggesting that a sense of belonging is important in academic persistence, and that support from the institution, faculty, 
and community impacts such persistence, especially for students of color in advanced-degree programs in which the students are the ethnic minority.

Achieving relatedness, or a sense of community, with other doctoral

learners is even more challenging in courses delivered online. While I am not a person of color, the broad focus of this chapter is social inequality, a topic of importance to me personally. The emergent theme of family and community support highlighted learners in the study who were first-generation graduate students. As I am a first-generation doctoral learner, I personally identified with this theme, and this made me reflect more deeply on my academic experiences. The participants in the study repeatedly referred to challenges in understanding the academic and social

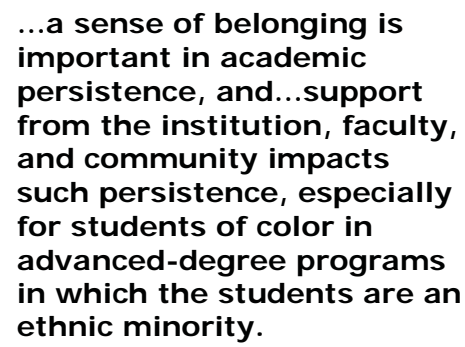

"system." Not being familiar with the institutional norms, socialization patterns, and protocols for reaching out to faculty members contributed to feelings of isolation. The message of this chapter parallels the challenges to socialization and learning online, in which time and space can create psychological distance, and hence feelings of isolation. I am fortunate to be currently enrolled in a doctoral program delivered online where building a sense of community has been the central focus. Through residency events, interaction with peers and faculty through the collegeadministered online scholar network, engaging in publishing and presentation opportunities offered by the college, and through the steadfast and caring disposition of my dissertation committee, I have not only overcome feelings of isolation but also achieved relatedness with my doctoral community.

Stigma is often attached to distance education. Questions of quality and feasibility persist. Is it equal in quality to the face-to-face counterpart? How does one overcome the psychological distance that may occur? Is this delivery method good enough to produce scholars of merit? These questions are further compounded by the prominence of online doctoral programs designed for working adults, which begs the central question: Can online doctoral learners who are also working adults engage in scholarly inquiry equal to that of full-time doctoral learners in campusbased programs? The answer to this question hinges on what is meant by community and the importance of community in motivating doctoral learners to consistently excel at scholarly inquiry. As researchers have noted, psychological distance is a phenomenon that may occur in either face-to-face or distance education (Moore \& Kearsley, 2012). Psychological distance may be caused by differences in time, space, ethnicity, or lack of common experience. The future of doctoral learning rests on the realization that excellent scholarly inquiry is as much influenced by relatedness as it is by competence. These constructs work hand in hand. When viewed in this light, the juxtaposition of pure face-to-face scholarly inquiry with part-time online scholarly inquiry becomes a false dichotomy. The future of doctoral learning is a future where such false dichotomies atrophy, where excellence in scholarly inquiry is defined not by delivery method but by the merit of contribution to the body of scientific knowledge. Whether through online, face-toface, or hybrid delivery methods, the future of doctoral learning relies on reducing social inequality through providing greater access to doctoral study, fostering a sense of community for doctoral learners, providing access to resources that support such learning, and encouraging scholarly endeavors, regardless of the delivery method. For the past two years, I have been fortunate to participate in such an endeavor, one which is changing what it means to engage in doctoral inquiry.

I nSight: A J ournal of Scholarly Teaching 


\title{
References
}

Moore, M.G., \& Kearsley, G. (2012). Distance education: A systems view of online learning (3rd Ed.). Belmont, CA: Wadsworth.

Winkle-Wagner, R., Johnson, S., Morelon-Quainoo, C., \& Santiague, L. (2010). A sense of belonging:
Socialization factors that influence the transitions of students of color into advanced-degree programs. In S. Gardner \& P. Mendoza (Eds.), On becoming a scholar: Socialization and development in doctoral education (pp. 179-199). Sterling, VA: Stylus.

\section{Evolving into Scholars}

\author{
Margie Watts \\ Doctoral Learner, Organizational Leadership \\ Grand Canyon University
}

The doctoral process is one that evolves. Learners grow and develop both personally and professionally as a result of their educational journey. While most come to the process with a multitude of life experiences, they continue to define and redefine themselves. Doctoral learners hone their skills as researchers, critical thinkers, and writers. They develop the art of balancing their personal life, their professional life, and their commitment to their educational pursuits. Personal challenges can arise when learners find themselves in new educational environments where there is no diversity of gender, race, religion, or sexual orientation. This may cause some to become isolated, while others may use this as an opportunity to become more familiar with individuals whose ideas and values differ from their own. The more that learners avail themselves of varied experiences and opportunities during the doctoral journey, the more valuable will be their evolution process.

Several issues related to social identity have been discussed. However, the issue of the doctoral learner's age has not yet been examined. Age can be a key element in how learners are accepted by faculty and by peers within the doctoral community. Learners wonder why those who are more senior are pursuing their degree when they are close to the end of their career. Common questions such as "Why are you here?" or "What are you going to do with your degree when you are finished?" can be found offensive to active learners who want to further develop as lifelong learners. Those who are committed learn to adjust to the questions, comments, and raised eyebrows with humor and determination, and stake their claims as valuable members of the doctoral learning community. Learners at the other end of the

The more that learners avail themselves of varied experiences and opportunities during the doctoral journey, the more valuable will be their evolution process.

spectrum, the "Doogie Houser" protégées, can certainly be presented with challenges of their own. Because of their age, they are deficient in both life and professional experiences. Who will value their opinions? Who will take them seriously in the learning community? Like the senior students and those in between, young learners must approach the doctoral process with positive determination.

Participation in a grounded doctoral cohort offers participants weekly opportunities to engage in rich discussions with peers from varied personal and professional backgrounds. During these discussions, there are opportunities to synthesize literature and research, and to share opinions and resources Camaraderie develops and learners are provided with opportunities to coach each other and celebrate victories through the peaks and valleys of the doctoral journey. These interpersonal relationships add great value to the learning community. 
Participating in all classes, as a group, allows learners to build on past learning experiences, thus strengthening the outcomes of future learning.

\title{
Reference
}

Gardner, S. K. (2010). Doctoral student development. In S. Gardner \& P. Mendoza (Eds.), On becoming a scholar: Socialization and development in doctoral education (pp. 203-221). Sterling, VA: Stylus.

\section{Adult Learners Pursuing Doctoral Education}

\author{
Riann Balch \\ Doctoral Learner, Organizational Leadership \\ Grand Canyon University
}

Becoming a doctoral learner is a process. As adult learners, doctoral students have a unique variety of beliefs, experiences, and circumstances that influence their learning styles and readiness to become doctoral learners. Unlike other forms of learning, doctoral learning requires a high degree of self-directed and interdependent learning, as well as the ability to engage in detached reflection, critical thinking, and innovative thought. Faculty and administrators can support adult learners by providing instruction, guidance, and infrastructure appropriate to the learner's stage of development in the process of becoming a doctoral learner. Kasworm and Bowles (2010) present three components of adult learning-selfdirected and critically reflective thinking, identity formation through transformational learning, and participation in communities of practice-as they relate to the process of becoming a doctoral learner. Based on these perspectives, strategies and recommendations to support doctoral learners are provided for faculty members, university administrators, and external agencies.

Today, most doctoral students are not solely engaged in the pursuit of education. They are working adults, busy running meetings, raising families, and taking care of their older parents. They are diverse in gender, ethnicity, culture, nationality, and socioeconomic status. Given this broad spectrum of learners, it is imperative that universities be prepared to support the changing needs of doctoral learners. The opposite is also true; prospective students must understand the responsibilities and be willing to make the changes necessary to become doctoral learners. During the formative stages of doctoral education, it is incumbent upon students to identify their personal needs and interests, and seek resources to support discovery and self-determination. University faculty and administrators can assist by providing clear expectations, an environment of trust and respect, and flexibility in program design. As students progress, they must form their identities as doctoral learners through critical reflection and engagement. Faculty and administrators can assist by facilitating awareness of distorted and limiting views, providing opportunities for service-learning and participatory action research, and offering interdisciplinary doctoral degrees. Finally, doctoral students should immerse themselves

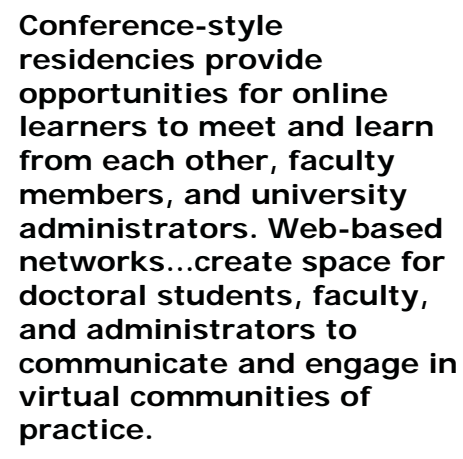

in their area of interest by participating in communities of practice. University faculty and administrators can assist by facilitating communities of practice through writing groups, research laboratories, and action research groups. 
Becoming a doctoral learner is challenging in any setting, but perhaps most difficult in the online academic environment. Universities offering online programs have developed innovative methods of supporting students in their journey to become doctoral learners. Web-based discussion forums facilitate course specific discussion. Conference-style residencies provide opportunities for online learners to meet and learn from each other, faculty members, and university administrators. Web-based networks, such as Grand Canyon University's DC Network, create space for doctoral students, faculty, and administrators to communicate and engage in virtual communities of practice. Hybrid cohort models have also been developed, merging campus-based night classes with online methodologies, offering perhaps the best of both worlds. Virtual technologies such as Skype may also add to a university's ability to connect with students in a more personal manner. Regardless of the setting, however, the critical issue is the student's ability to develop selfdirected learning skills; , engage in detached reflection and critical thinking, and participate in communities of practice. Despite the strategies discussed, many students continue to lack these abilities. Future research might seek to identify additional methodologies for helping doctoral students to understand, embrace, and develop the skills necessary to fulfill their roles and responsibilities as doctoral learners. Further, in their selection process, universities might consider prospective students' aptitudes related to self-direction, ideological rigidity, and collaboration.

\section{Reference}

Kasworm, C., \& Bowles, T. (2010). Doctoral students as adult learners. In S. Gardner \& P. Mendoza (Eds.), On becoming a scholar: Socialization and development in doctoral education (pp. 223-241). Sterling, VA: Stylus. 